\title{
An unusual case of postoperative ascites after cesarean section
}

\author{
Namrita Sandhu', Sanjay Singh ${ }^{2 *}$
}

\begin{abstract}
${ }^{1}$ Department of Obstetrics and Gynecology, Army College of Medical Sciences, New Delhi, India
${ }^{2}$ Department of Obstetrics and Gynecology, Base Hospital Delhi Cantt, New Delhi, India
\end{abstract}

Received: 26 March 2020

Accepted: 29 April 2020

\section{*Correspondence:}

Dr. Sanjay Singh,

E-mail: drsanjaysingh@gmail.com

Copyright: (c) the author(s), publisher and licensee Medip Academy. This is an open-access article distributed under the terms of the Creative Commons Attribution Non-Commercial License, which permits unrestricted non-commercial use, distribution, and reproduction in any medium, provided the original work is properly cited.

\begin{abstract}
Post-operative ascites following caesarean section is rarely reported in pregnancy. Ascites has multiple etiologies including malignancies, liver cirrhosis, intraperitoneal infections and trauma. Authors report a case of post-operative ascites following caesarean section performed at around 37 weeks of gestation. The patient was normotensive. The diagnosis and treatment of ascites as well as the pregnancy outcome is presented. Literature review of ascites in pregnancy is discussed as well. This case was that of an idiopathic ascites with no definitive cause. An allergic or inflammatory peritoneal reaction may be the most likely cause for this complication.
\end{abstract}

Keywords: Ascites, Inflammatory peritoneal reaction, Post cesarean

\section{INTRODUCTION}

Postoperative ascites, which can be caused by different factors, is a very rare complication of caesarean delivery. Such patients need thorough evaluation. Even after a detailed examination and investigation, one may not be able to pin point the cause in every case. However, if no definitive cause for the fluid accumulation is identified, the most likely explanation is idiopathic, allergic or inflammatory reaction of the peritoneum ${ }^{1}$

\section{CASE REPORT}

Authors present one such case of a 32-year-old, G2P1L1 lady, a known case of hypothyroidism on eltroxin, with post LSCS status, at 36 weeks +6 days period of gestation, with breech presentation. She presented with complaints of pain abdomen since one day. On examination, her vitals were stable with normal BP record. As she was found to be in labour she was taken up for an emergency LSCS. She delivered a healthy baby girl weighing $2.5 \mathrm{~kg}$. Immediate post op period was uneventful. On post-operative day 1, patient's vitals were stable. Lochia was healthy. Post op hemoglobin was 9.5 $\mathrm{g} / \mathrm{dl}$ with a total leukocyte count being $13,000 \mathrm{cell} / \mathrm{mm}^{3}$. Urine output was $2500 \mathrm{ml}$ against a total intake of 3200 $\mathrm{ml}$.

On post-operative day 3 , she developed abdominal distension which was accompanied with dull aching pain and one episode of vomiting. There was no history of fever, chest pain, dyspnoea, hematemesis, malena or jaundice. All the relevant laboratory investigations were sent out. ECG, 2D echo, computed tomography (CT) scan of abdomen were ordered as part of the special investigation to arrive at a diagnosis. Colour doppler inferior vena cava and hepato portal axis was done to rule out thrombosis. Ascitic tap was performed and the fluid was sent for analysis.

Echo was normal, with ejection fraction being $>60 \%$. Colour doppler showed normal study. Ultrasound was suggestive of gross ascites and mild hepato splenomegaly. The blood biochemistry revealed the following results: serum creatinine $1.89 \mathrm{mg} / \mathrm{dl}(0.6-1.4$ $\mathrm{mg} / \mathrm{dl})$ and blood urea nitrogen $42 \mathrm{mg} / \mathrm{dl}(8-25 \mathrm{mg} / \mathrm{dl})$, total protein $6.8 \mathrm{gm} / \mathrm{dl}$, albumin 2.3 (normal $3.5-5.5$ $\mathrm{gm} / \mathrm{dl}$ ). Ascitic fluid analysis was suggestive of high 
serum-ascites albumin gradient or gap (SAAG). Predominant cells were lymphocytes. Ascitic fluid cultures for aerobic/ anaerobic organisms and mycobacterium tuberculosis did not grow any organisms. No malignant cells were noted on cytology.

Patient was being managed with the provisional diagnosis of ascites with the suspicion of? Bud chairi syndrome. In view of the ascites, tablet aldactone was started. A high protein, low salt diet was advised. Injection albumin $20 \%$ in $100 \mathrm{ml}$ NS was administered over 4-6 hours daily till albumin levels returned to normal.

Despite these measures, patient's abdominal distension continued to increase and on post-operative day 7 , she developed severe distension of abdomen causing breathing difficulty and oozing of ascitic fluid from the incision site, for which she had to undergo paracentesis. 2 litres of ascitic fluid was drained. Patient improved symptomatically post procedure. Patient was transfused 2 Units of blood in view of low $\mathrm{Hb}$. Afterwards patient was managed conservatively with intravenous antibiotics, tab aldactone and Injection albumin and daily dressing of wound site and high protein diet.

Authors noticed that her ascites gradually started to settle around the $9^{\text {th }}$ post-operative day and she showed considerable improvement by day 14 . The ultrasound done on post-operative day 15 was normal, with no features of ascites and she was discharged on postoperative day 16. She was kept on follow up for the next 6 months. Her recovery was smooth.

\section{DISCUSSION}

Ascites is defined as the accumulation of fluid in the peritoneal cavity. There are many different types of ascites including pancreatic, bilious, malignant, chylous, and tuberculous. ${ }^{2}$ Chylous ascites is usually due to the obstruction of lymphatic channels and leakage of lymphatic fluid into the peritoneal cavity via a fistula from dilated retroperitoneal lymphatics. ${ }^{3}$ Chylous fluid is high in triglyceride content and the diagnosis is usually made when the concentration is greater than $200 \mathrm{mg} / \mathrm{dL}$. Chylous ascites can be due to a myriad of clinical conditions. Malignant tumors account for the majority of cases of chylous ascites, with lymphoma being the most commonly cited tumor. ${ }^{3,4}$ Mesenteric tumors, liver cirrhosis, abdominal trauma, infections including disseminated tuberculosis and lymphatic filariasis are common causes in underdeveloped countries. ${ }^{3}$ Postoperative development of chylous ascites has also been reported especially following abdominal surgery and pelvic lymph node dissection. ${ }^{4}$ In pregnancy, chylous ascites is an extremely rare occurrence. After a review of the literature, authors found six reported cases. ${ }^{5}$

The development of ascites has also been linked to preeclampsia in multiple published studies., ${ }^{6,7}$ In the context of preeclampsia, ascites is usually due to hypoproteinemia and a low albumin/globulin gradient resulting in a low intravascular oncotic pressure. ${ }^{8}$

This case was an unusual case of ascites, developing following an elective caesarean delivery, with no evidence of bleeding, iatrogenic injuries to the bowel or urinary tract or any peritoneal contamination. A thorough postoperative hematological, biochemical and cytological analysis of the ascitic fluid was done, however, no definite cause could be found out. Patient was managed with intravenous antibiotics, diuretic, intravenous albumin, high protein diet and her ascites gradually resolved over a period of a week.

The possibility of an inflammatory peritoneal reaction needs to be kept in mind. However, authors just have isolated case reports on inflammatory peritoneal reaction as a cause of post op ascites in the literature. These reports are of patients who had undergone gynecological procedures.

Postoperative ascites of unknown origin has been reported following laparoscopic appendicectomy, laparoscopic cholecystectomy, laparotomy for resection of ovarian cysts and for myomectomies, laparoscopic salpingectomy, laparoscopic gynecologic surgery, diagnostic laparoscopy, hysteroscopy and peritoneal dialysis. ${ }^{9-11}$

Previous case reports on the development of postoperative idiopathic fluid accumulation following caesarean delivery suggested the possibility of allergic reaction to chemical agents used during laparoscopy or laparotomy (antiseptic peritoneal lavage and methylene blue dye) or some substances used (carbon dioxide, electricity, light/ heat, diathermy and latex powder). However, the patient was not administered any specific chemical agent or intraperitoneal diathermy during the caesarean section. ${ }^{12,13}$

An association between a low serum albumin and infection has been found in intensive care unit patients and serum albumin has been noted to be low in sepsis (below $2.0 \mathrm{~g} / 100 \mathrm{ml}$ ). ${ }^{14}$

This case report describes an unusual case of ascites of unknown origin following an elective caesarean delivery. Complete recovery occurred in this case, although authors could not determine the etiology of ascites conclusively.

\section{CONCLUSION}

Post-operative ascites is a very rare complication of caesarean delivery. Such patients need thorough investigation to rule out the possibility of an intraperitoneal bleed or an iatrogenic injury to a vessel, bowel or bladder during the caesarean section. However, if no definitive cause for the fluid accumulation can be identified, the most likely explanation is idiopathic 
allergic or inflammatory reaction of the peritoneum. With this case experience, authors suggest that after draining the fluid if required, such patients recover well and no further intervention is required.

Funding: No funding sources Conflict of interest: None declared

Ethical approval: Not required

\section{REFERENCES}

1. Jiang W, Cong Q, Wang YS, Cao BR, Xu CJ. Postoperative ascites of unknown origin after laparoscopic gynecologic surgery: a 5-year experience of 8 cases and review of the literature. Surg Laparose Endosc Percutan Tech. 2012;22(3):e129-e131.

2. Thompson KA, Al Khabbaz A. Incidental chylous ascites at the time of cesarean section. Obstet Gynecol. 2015;2015:530210.

3. Cardenas A, Chopra S. Chylous ascites. Am J Gastroenterol. 2002;97(8):1896-900.

4. Almakdisi T, Massoud S, Makdisi G. Lymphomas and chylous ascites: review of the literature. The Oncol. 2005;10(8):632-5.

5. Habek D, Habek JC, Vujic B. Nontraumatic chyloperitoneum in pregnancy. Eu J Obstet Gynecol Reprod Biol. 2005;122(2):245-7.

6. Vaijyanath AM, Nayar B, Malhotra N, Deka D. Massive ascites in severe pre-eclampsia: a rare complication. J Obstet Gynaecol Res. 2002;28(4):199-202.

7. Chawla S, Kumar BP, Bhalla M. Case of ascites in pre- eclampsia. Med J Arm Forces India. 2012;68(3):257-9.
8. Brown MA, Zammit VC, Lowe SA. Capillary permeability and extracellular fluid volumes in pregnancy induced hypertension. Clin Sci. 1989;77(6):599-604.

9. Feretis M, Boyd-Carson H, Karim A. Postoperative ascites of unknown origin following laparoscopic appendicectomy: An unusual complication of laparoscopic surgery. Case Rep Surg. 2014;2014:549791.

10. Milingos S, Protopapas A, Chatzipapas I, El Sheikh A, Liapi A, Michalas S. Postoperative ascites developing after laparoscopic surgery can become a difficult diagnostic dilemma. J Am Assoc Gynecol Laparoscop. 2001;8:587-90.

11. Zhao $X$, Wang $M$, Huang $X$, Yu $H$, Wang $X$. Idiopathic postoperative ascites after laparoscopic salpingectomy for ectopic pregnancy. J Minimal Inv Gynecol. 2005; 12:439-41.

12. Rabiei M, Darvish S, Ghozat R. An unusual case of post-operative ascites after cesarean section delivery. Case Rep Clin Pract. 2016;1(3):68-70.

13. Gado A, Badawi H, Karim A. An unusual case of peritonitis following a caesarean delivery. Alexandria J Med. 2018;54(4):369-71.

14. Villota ED, Mosquera J, Rubio J. Association of a low serum albumin with infection and increased mortality in critically ill patients. Intens Care Med. 1980;7:19-22.

Cite this article as: Sandhu N, Singh S. An unusual case of postoperative ascites after cesarean section. Int J Reprod Contracept Obstet Gynecol 2020;9:2635-7. 